upon the comet, observations of much value may be received from Melbourne.

Mr. E. A. Fry, writing from Birmingham, incloses an extract from the Anglo-Brazilian Times of February 24, wherein M. Liais publishes the rough approximation to the elements, which the Emperor of Brazil telegraphed to the Academy of Sciences at Paris. M. Liais states that he had combined the two directions observed at Rio on the $4^{\text {th }}$ and 8 th inst. with the information in relation $t>$ the appearances observed at other places to arrive at some indication of the nature of the orbit, and with such meagre data it is not surprising that his figures should differ so greatly from Mr. Finlay's. He suggests that the object which several American astronomers mention having remarked during the totality of the solar eclipse of January I I in California, which was "distinct from the fixed stars and planets," and conjectured to be an intra-Mercurial body, "may have been this comet:" not a very happy suggetion if we are to rely upon Mr. Finlay's elements, since at the time in question the comet would have been situated $22^{\circ}$ west and $23^{\circ}$ souti of the sun.

Other notices received describe the brilliant appearance of the tail in the first week of February, but supply no particulars with reference to the position of the nucleus.

\section{METEOROLOGICAL NOTES}

THE storm of December 28, 1879 , will long stand out among British storms, not only as having occasioned the fall of the Tay Bridge, but also as having presented peculiarities which, taken together, are, so far as observation goes, unprecedented in these islands. Some of the more important of these peculiarities were brought before the meeting of the Scottish Meteorological Society on March Io by Mr. Buchan. Of these the most remarkable were the barometrical fluctuations, which were quite extraordinary along the central path of the storm from Barra Head to Wick. The barometric readings at Dhu Heartach Lighthouse, twelve miles south-west of lona, reduced to $32^{\circ}$ and sealevel, were, in inches, $29^{\circ} 615$ at IO A.M., $29^{\circ} 405$ at noon, 29.205 at I 30 P.M., $28 \cdot 905$ at 4 P.M., 28.705 at 5.5 P.M., $28 \cdot 645$ at 6 P.M., $29^{\circ}$ IO5 at 7 P.M., and $29.34^{2}$ at 9 P.M. Thus in one hour, from 6 to 7 P.M., the barometer rose 0.460 inch, or nearly half an inch. That this extraordinary fluctuation was no isolated phenomenon is shown by what was noted at the other lighthouses in the vicinity. Thus the barometer rose, from 4 to 9 P.M., 0.790 inch at Barra Head, from 5 to 9 P. M., 0.68I inch at Monach, $0^{*} 760$ inch at Ushenish, and 0.660 at Skerryvore; from 5.30 to 9 P.M., 0700 inch at the Point of Ardnamurchan; and from 6.I5 to 9 P.M., $0^{\circ} 590$ inch at Kyleakin. To north and south of the central path of the storm the fluctuations, though unusually large, fell far short of these amounts. From the observations made at the numerous stations of the Society, including the sixty Scottish lighthouses, the position of the centre of the storm could be determined with a close approximation to exactness hour by hour. From the results it is shown that the cyclone travellea on wards in each of the five hours respectivejy from 4 to 9 P.M., 30, 45, 53, 70, and 70 statute mile:, the rate of progress from 7 to 9 P.M. being thus about $3^{\frac{1}{2}}$ times the average rate in this part of Europe. The behaviour of the temperature of the air was e.jually striking, rising everywhere to from $52^{\circ}$ to $57^{\circ}$ as the centre of the cyclone advanced, and falling after it had passed. In other words, the temperature rose on this occasion to the average of the first week of June. From data supplied by Mr. Scott, of the Meteorological Office, the maximum velocity of the wind during the heaviest gusts was at the rate of 96 miles an hour at Aberdeen, 120 miles at Glasgow, and probably 150 miles at Seaham. Had pressure anemometers been pretty generally in action over Scotland on that evening, much higher wind-forces than these would doubtless have been recorded. The force of the wind was comparatively little felt to the north of the central path of the cyclone, owing to the low gradients in that direction, no notice of a storm being recorded, for example, at Cape Wrath, Stourhead, or the Butt of Lewis; but in the path of the centre and for some distance to southward, the storm swept onwards with destructive and uncontrolled fury, raising the spray in what reemed solid masses of water against the lantern of the Dhu Heartach Lighthouse, $\mathbf{1} 45$ feet high, which struck the glass with a sound like that of road metal, and completely overturning whole forests of Scotch firs 200 years old, so that not a single tree was left standing, and where the trees were fast rooted in the rock prostrating them along the ground after forming a joint near the roots by splintering this part of their trunks to a bundle of matches. The steepest gradient afforded by the barometric observations which were made is about I inch to $\mathrm{x}$ Io miles. Steeper gradients were noted during the great Edinburgh hurricane of January 24,1868 , when a gradient of $I$ inch to 72 miles occurred, and in accordance therewith an amount of damage was done to structures of solid masonry of which the storm of December last affords no parallel

Mr. Charles Carpmael, who has recently been appointed Superintendent of the Meteorological Service of the Dominion of Canada, has issued the first number of a Monthly Weather Review, presenting with fairly satisfactory fulness the weather and other meteorological phenomena of the Dominion for January, 1880 . The storms which in any way affected Canada during the month are detailed, and their tracks indicated. Weather-probabilities are issued by the office in Toronto at IO. AM. daily, and posted up at $35^{\circ}$ places in Canada within an hour from the date of issue. From an analysis of the successes and nonsuccesses of the weather-probabilities of the month given in the Revieze, it would appear that $80 \frac{1}{2}$ per cent. were fully verified, $93 \frac{1}{2}$ per cent. either fully or partly verified, leaving only $6 \frac{1}{3}$ per cent. of failures. The outstanding features of the meteorology of the month were the low mean pressure in the west, the bigh pressure in the east, and the very high temperature which prevailed at all the stations. The mean temperature for January, 1880 , was the highest yet recorded in any year at Toronto, thus offering a striking contrast to the weather which prevailed generally over Europe during the month. This meteorological service is under the deepest obligations to Prof. Kingston, through whose exertions chiefly it was called into existence. These arduous exertions have told seriously on his health, and he has been obliged to retire from the position of superintendent. $\mathrm{He}$ carries with him the best wishes of meteorologists coupled with a hope that in his retirement he will be able to continue his services in the furtherance of American meteorology.

In a twelfth contribution to meteorology, Prof. Loomis presents us with isobars for the United States, showing for January and July the mean pressure of the atmosphere from the observations made by the Signal Service of the War Department for the six years ending June, 1877 . In July pressure is highest in Florida, being 30 Ioo inches, from which it diminishes on advancing into the interior to 29.850 inches in Utah, rising again on proceeding west to about $30^{\prime} 100$ inches on the Pacific coast, in latitude $45^{\circ}$. This state of things is, roughly speaking, reversed in January, with, however, several noteworthy differences. The highest pressure, $30^{\circ} 25^{\circ}$ inches, is now in Utah, and the lowest generally round the coasts, falling to the minimum, 30'000 inches, at the entrance to Fundy Bay. The high pressure of the interior may be regarded as spreading over the States occupying the region from Minnesota to California. The slight break in it on the chart, as occurring about Cheyenne, will require confirmation from future observations. A second area of high pressure spreads over the larger portion of the south eastern and Southern States. These two distinct areas of high pressure are separated from each other by a region of lower pressure stretching in a south-west direction from Chicago, towards the Rocky Mountains. The discovery of this peculiarity in the winter-distribution of pressure in the States which, correctly we think, is ascribed to the path usually taken by the barometric minima of American storms in the earlier part of their course, constitutes, perhaps, the most valuable contribution to meteorology yet made by Prof. Loomis.

PROF. LOOMIS institutes an interesting comparison of the varying rates of progress of storm-centres, and shows that over the United States the rate of progress is twenty-six miles an hour, whereas, over the Atlantic, it is only fourteen miles, and on the continent of Europe, as shown by Dr. Neumayer, it does not exceed sixteen miles an hour. In this connection it is pointed out that the winds on the Atlantic are stronger than they are over either of the continents, and the winds of central Europe are stronger than the winds of the United States, rela. tions that suggest whether friction may not be concerned in determining the rate of the onward progress of storms. As bearing, however, more immediately on this question, Prof. Loomis draws attention to this important distinction between American and European storms, viz., from the Rocky Mountains to the Atlantic Ocean storms advance from a drier to a more humid atmosphere, whereas in Europe, while storms pursue their easterly course, they proceed from a humid to a drier atmo- 
sphere. An examination of the rate of progress of storms in north-western Europe, as compared with the rate in the interior of the continent, would contribute important data to the inquiry here raised.

\section{PHYSICAL NOTES}

ACCORDING to a theory of crystallogenesis recently brough before the Bologna Academy by Signor Marangoni, the forma tion of crystals is due to composition of molecular vibrations. As vibrating plates give the symmetrical nodal lines of Chladni, so solid bodies, in their vibrations in three directions, produce nodal surfaces, which correspond to the cleavage surfaces of crystals. The author (confining himself to simple substances) considers a chemical molecule as one produced in general by union of two atoms rotating round one another; a physical, as arising from two chemical rotating round one another. If these motions do not occur in the same plane, we have motions of a pendular nature in the three directions of space. Where the times of vibration are in simple ratios to each other, crystals are formed ; where, again, the relations are complicated or incommensurable, we have liquids; and in the gaseous state, the physical molecules break up into the chemical. If the ratios of the three motions are $1: 1: 2$ we have 4 osculating planes, cnclasing a tetrahedron. The common orientation of these pjenes hin all molecules preduces planes of cleavage. If the $r$ utios are $I: 1: 3$, there are 6 osculating planes and a rhombohedron. By means of a tuning-fork throwing a soap-bubble into vibration, the author illustrates his hypothesis. He deduces a rumber of crystallographic properties, further assuming that parallel-directed vibrations attract each other, while opposite repel.

A SERIES of experiments in spectrum-analytical comparison of gas, sun, day, and the electric light has been lately made by Herr Meyer (Carl's Zeilsch. für angew. Electr.-Lehre, I, p. 320, 1879). He used both Vierordt's method and a method first suggested by Bohn; in the latter a Nicol prism is fixed before one-half of a slit and receives the light from one source; behind it is the Nicol, rotatable in a graduated circle of Wild's polaristrobometer. The light beam passing tirrough botb prisms strikes a rectangular glass prism, which reflects it into the spectrum apparatus. The second slit-half is illuminated either directly or through a second rectangular prism from the second light source. The numbers show that the brightness of the colours in the gasspectrum, compared with that in sun or daylight and the electric light, steadily decreases from the red to the violet end of the spectrum. As sunlight is considerably brighter in the middle parts of the spectrum than the electric light, the latter should appear yellow with the former; and in a Ritchie photometer the surface illuminated by the electric light did indeed appear yellow like an orange, in comparison with that illuminated by the sun. Another interesting fact elicited is that in daylight there is comparatively more red and yellow, and less blue and violet light than in sunlight.

LAST year M. Van Rysselberghe devised a regulator rigorously isochronous in theory, that is, the movable masses of which were displaced exactly along a parabola. It was considered, however (in the Belgian Academy), that practically the number of articulations was too great to allow of the isochronism being realised. $M$. Van Rysselberghe has now hit upon a different and very simple combinalion, in which the articulations are reduced to a minimum, and which gives a very close approximation to the parabola, though not that figure rigorously. He has a model, the velocity of which is maintained constant to nearly $\frac{1}{100}$, while the force transmitted to the vanes and absorbed by them, varies in the ratio of $I$ to 200 . He does not despair of pushing the precision to $\frac{1}{0000}$ (or less than a second a day). One special feature in the apparatus is a system of vanes designed to increase the resistance in a proportion slightly greater than that furnished by the increasing aperture of the moderator-lozenge. These vanes, on a straight horizontal axis, strike the air at different inclinations according to the resistance to be developed, being moved by suitable gearing, and automatically into various positions from the horizontal to the vertical. There is also a system of compensation for variations of temperature. This regulator is expected to be of great service in application to registering at a distance, to chromographs, to equatorial telescopes, to siderostats, to telegraphs, and to industrial motors. (It is described in the Bulletin of the Belgian Academy, No. $x, 1880$.)
SOME experiments by Herr Reusch, with a view to determining the modulus of elasticity of ice, have been recently published (Ann. der Phys., No, 2). Rectangular prismatic lamellae of ice were obtained by pressing the edges of two beated plates of zinc, fixed parallel in a frame, into plates of ice, the ends being then cut with two other zinc plates in the frame. After careful measurement and weighing, the number of transverse vibrations of the tone given by the lamella supported near the onter fifth was determined by means of a Marloye sonometer ( 2 monochord $1 \mathrm{~m}$. long, with tuning-fork giving 256 vibrations per second). This was done, of course, in a room with the temperature below zero. Calculating according to the formula given by Seebeck, Herr Reusch found the arithmetic mean (from five experiments) of the modulus of elasticity $E$, in kilogrammes per square millimetre $=236^{\circ} 324$. The only previous determination known to him is that of Frankenherm (in Mousson's "Physics"), where $E=54 \mathrm{r}$, a number which he therefore thinks more than twice too great.

IN a recent paper in the Annalen der Physiz (No. 2), Herr Frohlich endeavours to prove that of the three electrodynamic fundamental laws enunciated by Clausius, Riemann, and Weber severally, as satisfying the principle of conservation of energy, that of Clausius-and, supposing unequal velocity of the two electricities in the galvanic current, the two others also-leads to theoretically unreliable and practically useless results.

\section{GEOGRAPHICAL NOTES}

LetTers have been received from Prof. I. B. Balfour, announcing that he had been safely landed by H.M.S. Seagult in Golbourn Bay, at the west end of Socotra, on February II, weather not pelmitting the vessel to go round to the principal port, Samarida. Prof. Balfour had formed pretty bigh expectations of the island from what he had heard, but these were greatly exceeded by the reality. The flora was found to be rich and varied, and 150 species of plants, some of great interest, had been obtained in a few days. Birds were numerous, as also reptiles and insects. There was plenty of water, and some splendid Dytisci. The geology was very perplexing, granite, limestone, and dioritic rocks being mixed up in an extraordinary manner.

WE are glad to see that the Geographical Society is doing its best to show honour to Prof. Nordenskjold and to give him a hearty welcome to this country. A distinguished deputation awaited his arrival at Portsmouth on Monday, but unfortunately the Vega did not appear, though by this time she has, most probably, arrived. The highest British mark of honour awaits the explorer-a dinner at Willis's Rooms, at which, we are glad to learn, the Prince of Wales will be present. We have said so much concerning the work of Prof. Nordenskjold that scarcely anything new is left to say either concerning himself or concerning his services to science in the voyage he has so successfully accomplished. Commerce is sure to follow up the pioneer work of the $V e g a$, and we hope that very soon the region explored will be garrisoned, as the Times puts it, by, meteorologists who will "watch the winds where they are born."

AT the meeting of the Geographical Society on Monday evening it was announced that Prof. Nordenskjold, who is already a Gold Medallist, had been elected an Honorary Corresponding Member. Mr. E. Hutchinson afterwards read a paper on the ascent of the Binue brancl of the Niger in 1879 by Ashcroft, an agent of the Church Missionary Society, in the little steamer Henry Venn. The party left Lokoja, at the confluence with the main river, on July 8 , and on $\mathrm{Au}$ gust 28 arrived opposite Yola in N. lat. $9^{\circ} 16^{\prime}$ and $\mathrm{E}$. long. $12^{\circ} 31^{\prime}$, some 364 miles to the eastward in a straight line. From Yola they proceeded past the junction of the Faro tributary, where Dr. Barth crossed in $185 \mathrm{r}$, and for about forty miles higher up, anchoring on September 4 off the town of Garawa, which lies some distance from the river bank. This place is situated in N. lat. $9^{\circ} 28^{\prime} 45^{\prime \prime}$ and $E$. long. $13^{\circ} 26^{\prime}$. As the river was falling fast, Mr. Ashcroft only ventured to go a few miles further up in a steam launch. The distance traversed by the Henry Venn Expedition, which had never been previously explored, is probably not far short of 150 miles, and of this an exceedingly good chart has been made by Mr. Flegel, a German who, in his anxiety to join in the exploration, accompanied the party as ship's clerk. It is satisfactory to learn that the natives, except at one spot, showed themselves particularly well-disposed. 